\title{
NUMERICAL AND EXPERIMENTAL ANALYSIS OF DYNAMIC PROPERTIES OF A COMPOSITE HYDRAULIC MICROHOSE
}

\author{
M. Bocian*, M. Lubecki**, M. Stosiak ${ }^{* * *}$
}

\begin{abstract}
The paper presents an analysis of driven vibrations of a hydraulic microhose made of a composite material. The test object was a hydraulic flexible hose with an internal diameter of $2 \mathrm{~mm}$ and a length of 960 $\mathrm{mm}$. The vibrations of the object were driven by the electrodynamic actuator, and they were recorded with a laser vibrometer. At the same time, numerical analysis of such an object was carried out using the finite element method. The results of numerical and experimental studies were compared and the possible causes of discrepancies were pointed out.
\end{abstract}

Keywords: Hydraulics, Microhydraulics, FEM, Vibrations.

\section{Introduction}

Such factors as automation and mechanization as well as optimization of dimensions and weight could cause increased vibrations in the surrounding of the machine. Also, the use of new materials usually with low internal damping, reduces the ability of the object to dissipate energy and damp vibrations. Higher and higher requirements for machines and technological processes cause an increase in dynamic interactions, resulting in increased vibrations and noise. (Fiebig et al., 2017, Chenxiao et al., 2012).

The problem of coincidences of mechanical vibrations and pressure pulsations in hydraulic systems can be considered in two ways (Wachel et al., 1994). The first one is that the vibrations of hydraulic elements could be excited by the pulsating flow (eg vibrations of piping systems or valves) (Luczko et al., 2014), and the second is that the pressure pulsation could be induced by vibrations of hydraulic elements (Stosiak, 2011). The pulsing flow of the fluid in the microhydraulic hose may cause mechanical vibrations of a periodic nature.

Excited vibrations of the microhydraulic hose may cause, among others, increased noise, accelerated wear and fatigue damage (Zachwieja, 2004, Makaryants et al., 2015). There is an intense development of numerical methods used to predict the influence of pulsating flows in hydraulic systems (Urbanowicz, 2017). Such calculations should be accompanied by experimental verification. This work is an attempt of numerical and experimental analysis of vibrations of a microhydraulic hose and determination of the usefulness of a selected numerical method.

Mirosław Bocian PhD.: Faculty of Mechanical Engineering, Wroclaw University of Science and Technology, Department of Mechanics, Materials Science and Engineering, Lukasiewicza 5, 50-371 Wrocław, PL, miroslaw.bocian@pwr.edu.pl

** $\quad$ Marek Lubecki M.Sc. Eng.: Faculty of Mechanical Engineering, Wroclaw University of Science and Technology, Department of Maintence and Operation of Logistics, Transportation and Hydraulic Systems, Lukasiewicza 5, 50-371 Wrocław, PL, marek.lubecki@pwr.edu.pl

*** Michał Stosiak DSc., PhD, Eng. Prof.: Faculty of Mechanical Engineering, Wroclaw University of Science and Technology, Department of Maintence and Operation of Logistics, Transportation and Hydraulic Systems, Łukasiewicza 5, 50-371 Wrocław, PL, michal.stosiak@pwr.edu.pl 


\section{Methods}

\subsection{Test stand}

The subject of the research was the Polyflex 2020N-012V30 elastic microhydraulic hose made by Parker Hannifin, containing in its structure an aramid braided layer. The internal diameter of the hose was $2 \mathrm{~mm}$, the external one $-4.9 \mathrm{~mm}$, and its length $-960 \mathrm{~mm}$. The hose was working in a hydraulic system whose diagram is shown in figure 1 . The object was divided into 8 parts by placing 9 equidistant points on its surface $\left(a_{0}, a_{1}, \ldots, a_{8}\right)$. At point $a_{0}$, the hose was fixed from the pump side and at point $\mathrm{a}_{8}$ from the system side. At point $\mathrm{a}_{3}$, an external vertical excitation was applied by attaching the Brüel \& Kjær 4809 electromagnetic vibration exciter, powered by the Brüel \& Kjær 2718 power amplifier. A sinusoidal waveform and the Sweep function were used. As a result of preliminary tests, the range of excitation frequencies was set from $1 \mathrm{~Hz}$ to $200 \mathrm{~Hz}$ and the time for $10 \mathrm{~s}$. The vibration velocity measurement in the vertical direction was carried out using OFV-505 single-axis laser head with the OFV-500 controller made by Polytec. The temperature of the system was kept constant at $42{ }^{\circ} \mathrm{C}$.

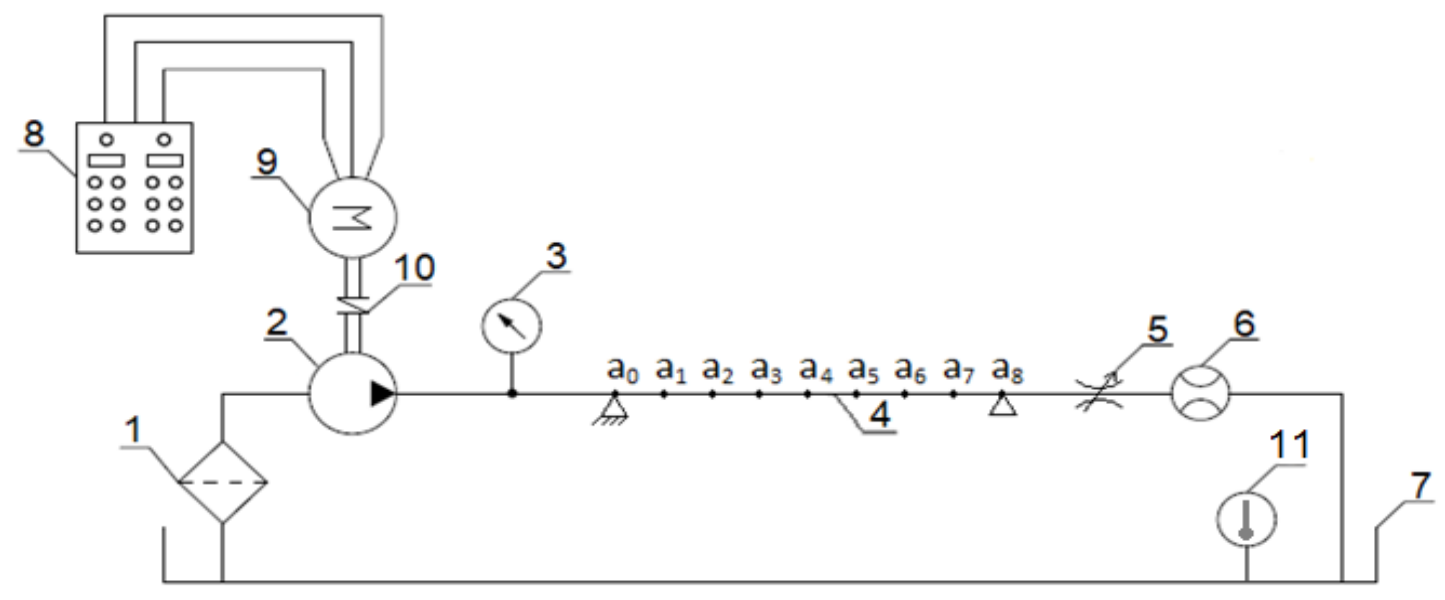

Fig. 1: Schematic of hydraulic system: 1 -filter, 2 - gear micropump, 3 - pressure gauge, 4 -tested microhose, 5 - preset throttle microvalve, 6 -flowmeter, 7 -tank, 8 -control cabinet, 9 -electric motor, 10 -torque indicator, 11 -temperature meter.

\subsection{Numerical model}

The numerical modal analysis was carried out in the Ansys 19.0 software. A solid geometric model of the longer part of the hose (from $a_{3}$ to $a_{8}$ ) was built. The discretization was carried out in the Mechanical module in such a way that 5 elements were obtained through the thickness of the hose and 180 elements on the length which gave a total of 17100 elements and 71214 nodes in the entire model. Material parameters were determined in a static tensile test. Fig. 2 shows the broken specimen after strength tests. The model was fixed at both ends to reflect the real conditions occurring during the experiment. A tension was also introduced by moving one of the ends by $1.45 \mathrm{~mm}$, which resulted in the axial force of $15.1 \mathrm{~N}$. The effect of gravity as well as the fluid inside the hose were taken into account. The results of the modal analysis are shown in Figure 3.

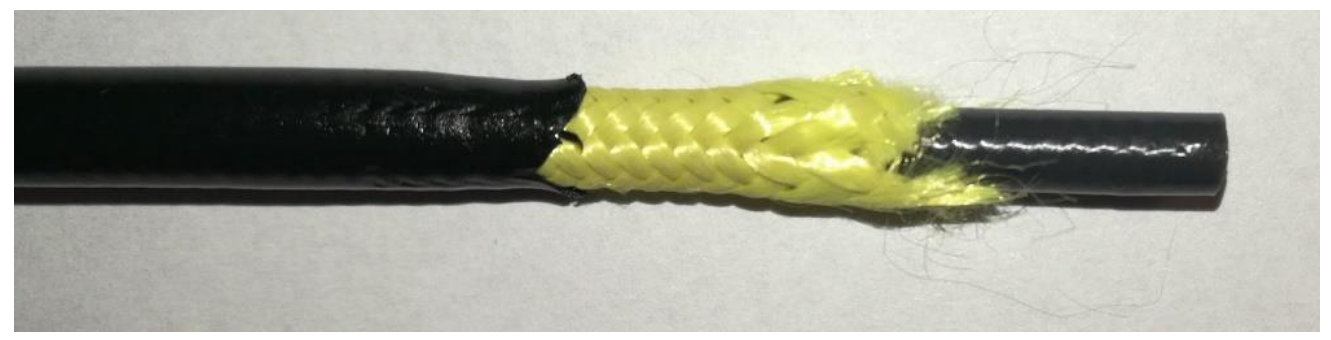

Fig. 2: Microhose after strength tests - visible layers of elastomer (inner and outer) and aramid braid 




Fig. 3: Shapes and frequencies of resonant vibrations obtained as a result of modal analysis - a) $25 \mathrm{~Hz}$, b) $51.5 \mathrm{~Hz}, c) 80.6 \mathrm{~Hz}, d) 113.4 \mathrm{~Hz}$.

\section{Results}

A hydraulic hose with such a small cross-section and a relatively long length will behave like a string. In the case of transverse vibrations of this type, the important parameter is the initial tension of the hose. Based on FEM calculations, the relationship between initial tension and resonant frequencies for individual vibration modes (Fig. 4) was shown. These calculations allowed to choose the right value of the tension in the model to match its vibration forms to the vibrations of the real system (Fig. 5) (in the real system, it was not possible to measure the initial tension of the hose).

The numerical analysis also showed a significant influence of the method of constraining the ends of the hose on resonant frequencies for individual vibration modes. As a result of experimental studies, it was observed that the flow rate as well as the average pressure in the system influence the value of natural vibration frequency. The increase in the flow rate causes the natural frequency to decrease, and the increase of the average pressure causes the natural frequency to increase (Fig. 6) (Bocian et al., 2018). However, the influence of the flow rate is stronger than that of a pressure in the measured range.

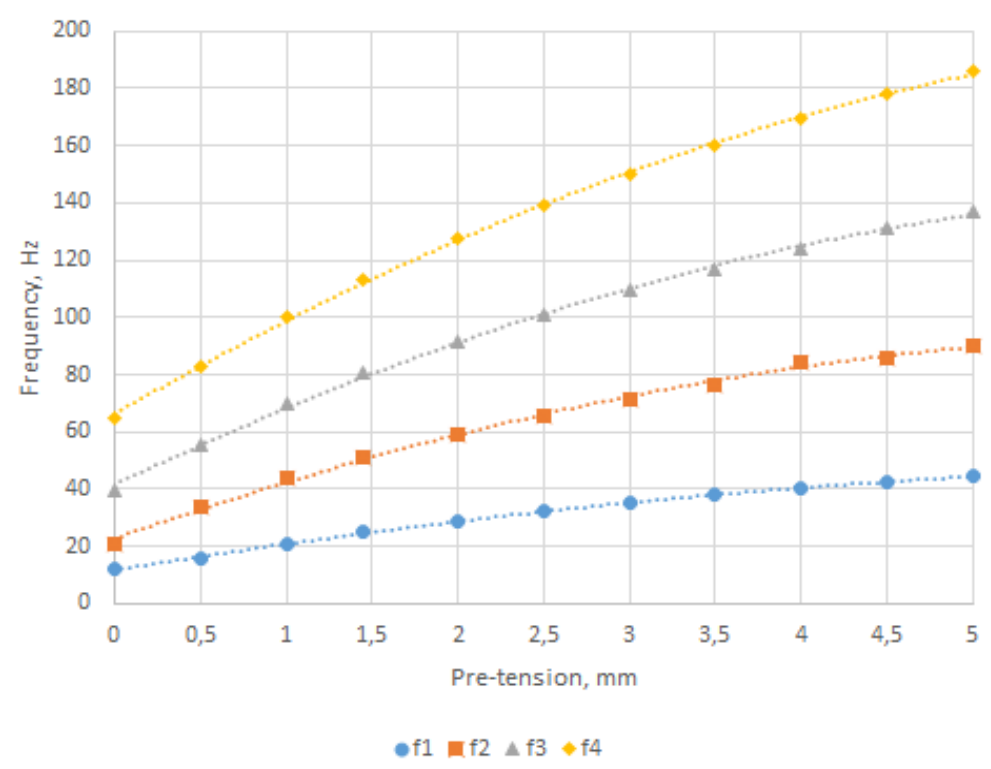

Fig. 4: The relationship between the pre-tension of the hose and the values of the first four natural frequencies obtained from the FEM analysis 


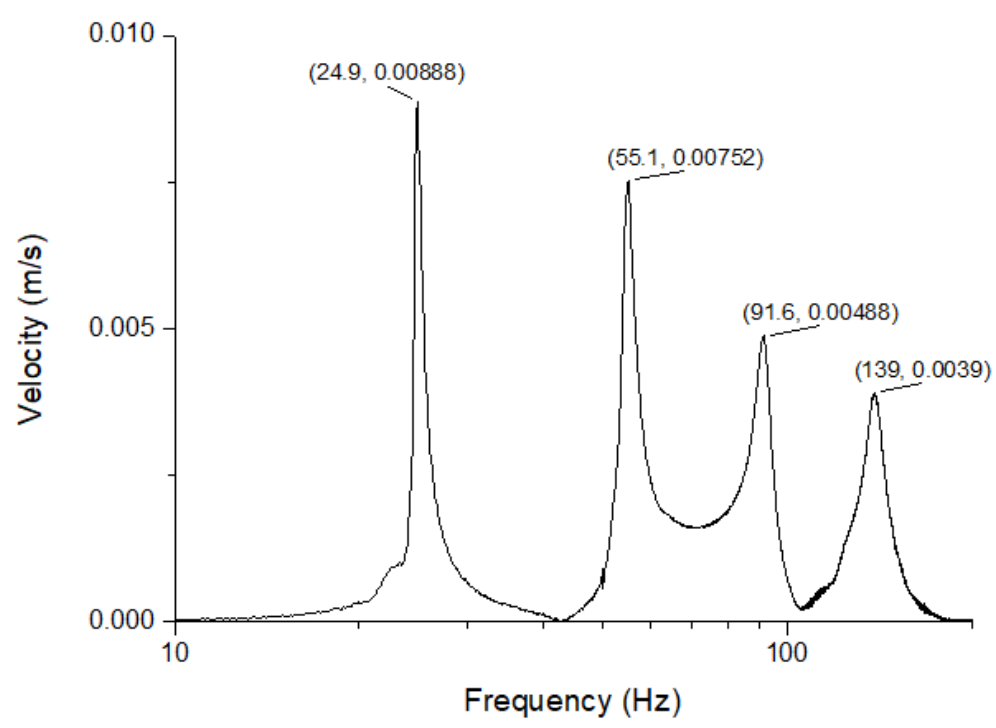

Fig. 5: Vibration velocity (in the vertical direction at point $a_{5}$ ) of the microhose as a function of the excitation frequency

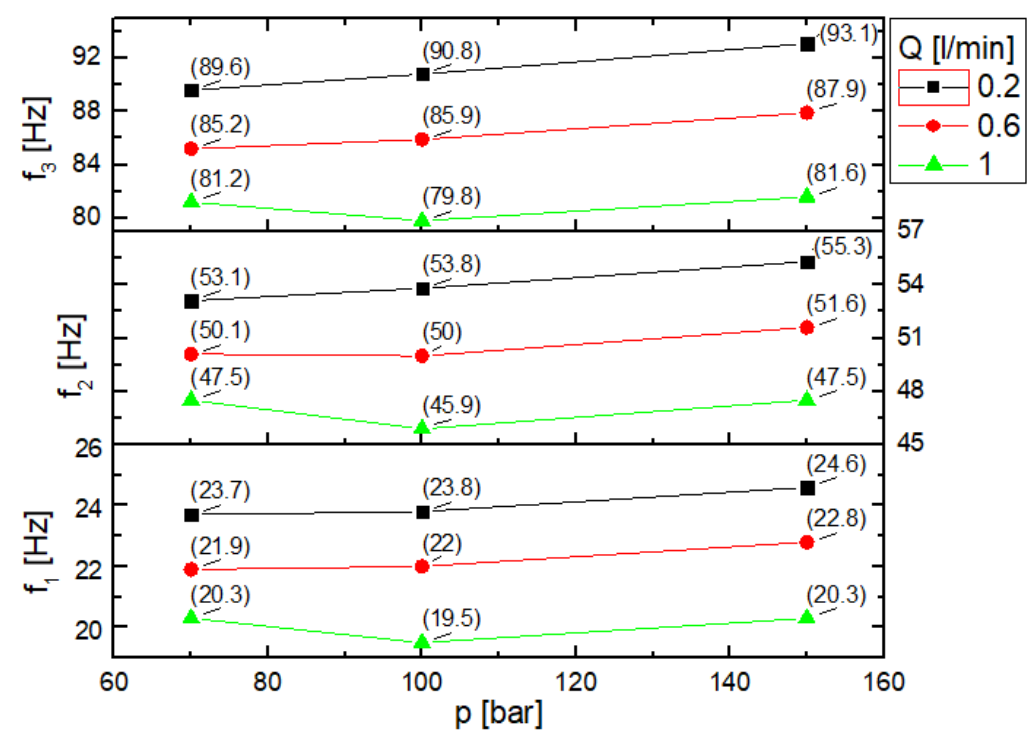

Fig. 6: Effect of pressure and flow rate in system on fundamental $\left(f_{1}\right)$, second $\left(f_{2}\right)$ and third $\left(f_{3}\right)$ free vibration frequencies of investigated microhose (Bocian et al., 2018)

\section{References}

Bocian, M., Lubecki, M., Stosiak, M. (2018) Experimental investigations of the vibration of hydraulic microhoses. Engineering Mechanics 2018 : 24th international conference, May 14-17, 2018, Czech Republic, pp 97-100

Chenxiao N., Xushe Z., (2012) Study of vibration and noise for the hydraulic system of hydraulic hoist. Proceedings of 2012 International Conference on Mechanical Engineering and Material Science (MEMS), pp 126-128

Fiebig W., Wróbel J. (2017) Two stage vibration isolation of vibratory shake-out conveyor. Archives of Civil and Mechanical Engineering, vol. 17(2), pp 199-204.

Łuczko J., Czerwiński A. (2014) Parametric vibrations of pipes induced by pulsating flows in hydraulic systems, Journal of Theoretical and Applied Mechanics, 52, 3, pp 719-730.

Makaryants G. M., Prokofiev A. B., Shakhmatov E. V., (2015) Vibroacoustics Analysis of Punching Machine Hydraulic Piping. Procedia Engineering Volume 106, pp 17-26

Stosiak M.: (2011) Vibration insulation of hydraulic system control components, Archives of Civil and Mechanical Engineering, vol. 13(1), pp 237-248.

Urbanowicz K. (2017) Modern Modeling of Water Hammer, Polish Maritime Research 24(3), pp 68-77.

Wachel, J.C., Tison, J.D. (1994), Vibrations in reciprocating machinery and piping systems, Proceedings of 23rd Turbomachinery Symposium, Texas A\&M University, College Station (Texas), pp 243-272

Zachwieja J., Gawda M. (2004) The nature of the vibrations of the pipe with the pulsatile flow of the working medium, Hydraulika i Pneumatyka, 4, pp 38-44 (in Polish). 